\title{
COMPARISON OF ONE-STEP NUCLEIC ACID AMPLIFICATION (OSNA) METHOD AND ROUTINE HISTOLOGICAL INVESTIGATION FOR INTRAOPERATIVE DETECTION OF LYMPH NODE METASTASIS in Polish Women with breast Cancer
}

\author{
Beata Smolarz ${ }^{1}$, Tomasz KrawczyK ${ }^{1}$, Boguseaw Westfal ${ }^{2}$, Rafae MaciejczyK ${ }^{2}$, \\ Marek Zadrożny ${ }^{2}$, Dariusz Samulak ${ }^{3,4,5}$, Magdalena M. Michalska ${ }^{5}$, Ewa Mojs ${ }^{6}$, \\ Maciej WILCZAK ${ }^{7}$, Hanna RomanowiCZ-MaKowsKa ${ }^{1}$
}

\author{
${ }^{1}$ Laboratory of Molecular Genetics, Department of Pathology, Institute of Polish Mother's Memorial Hospital, Lodz, \\ Poland \\ 2Department of Oncology, Institute of Polish Mother's Memorial Hospital, Lodz, Poland \\ 3 Department of Mother's and Child's Health, Poznan University of Medical Sciences, Poznań, Poland \\ ${ }^{4}$ Clinic of Gynaecological Surgery, Poznan University of Medical Sciences, Poznań, Poland \\ 5Department of Obstetrics and Gynaecology, Regional Hospital in Kalisz, Kalisz, Poland \\ 6Department of Clinical Psychology, Poznan University of Medical Sciences, Poland \\ ${ }^{7}$ Department of Medical Education, Poznan University of Medical Sciences, Poland
}

\begin{abstract}
Sentinel lymph node (SLN) biopsy is a part of the staging procedure in breast cancer patients. Intraoperative molecular analysis for SLN metastases using the one-step nucleic acid amplification (OSNA) method based on reverse-transcription loop-mediated amplification (RT-LAMP) has already been validated in breast cancer.

In this study, we compare the intraoperative OSNA method to our routine histological investigation.

To evaluate the performance of OSNA in comparison to histology, analysis of 74 SLN from 60 breast cancer patients was conducted with both methods.

Of the 22 histologically positive samples, 14 were attributed to macrometastases $(++)$ in the OSNA-CK19 assay and 8 to micrometastases $(+)$. Two samples negative in histopathology were positive in the OSNA method (micrometastases + ).

Our results show that OSNA is an excellent method for the detection of metastases in lymph nodes and can be applied as an intraoperative diagnostic approach. Intraoperative molecular analysis for SLN metastases using the OSNA method reduces the number of admission days and duration of surgery. To our knowledge this is the first study referring to Polish women.
\end{abstract}

Key words: OSNA, breast cancer, sentinel lymph node, mRNA CK19.

\section{Introduction}

Breast cancer is the most common cancer in women worldwide. The risk of breast cancer increases with age, family cancer history, unusual hormonal and reproductive factors, unhealthy lifestyle and many other factors [1].
Sentinel lymph node (SLN) biopsy has recently become a conventional standard surgical method in the treatment of breast cancer patients [2]. Sentinel node (SN) is defined as the first lymph node which receives lymphatic drainage from the primary tumour. 
The literature data suggest the utility of novel molecular analysis: reverse-transcription loop-mediated amplification (RT-LAMP) - one-step nucleic acid amplification (OSNA) assay for the detection of metastatic deposits in lymph nodes of breast cancer patients [3].

This molecular diagnostic assay detects the expression level of cytokeratin 19 (CK19). Cytokeratin 19 mRNA is a suitable marker for identifying breast cancer deposits in lymph nodes because virtually all breast cancers express this cytoskeleton protein [4].

Cytokeratins (CKs) constitute the largest intermediate filament protein subgroup and represent a multigene family with more than 20 different types of polypeptides that are divided into acidic type I (CK9CK20) and basic type II (CK1-CK8) keratins [5].

Due to its high sensitivity, CK19 is the most frequently used marker for the RT-PCR-mediated detection of tumour cells disseminated in lymph nodes, peripheral blood, and bone marrow of breast cancer patients [5].

In recent studies performed in Japan and Western Europe OSNA analysis has been found to be a potentially valuable intraoperative method for the detection of lymph node metastases in patients with colorectal and breast cancer [6-10].

In the present study, we compared an intraoperative method, one step nucleic acid amplification (OSNA), to our routine histological investigation.

\section{Material and methods}

\section{Patients}

An intraoperative clinical study was conducted from May 2011 to January 2012 at the Institute of Polish Mothers Memorial Hospital, Lodz, Poland. In total, 74 SLN samples from 60 patients were analysed by OSNA assay and routine histopathology examination. In the histopathological examination macrometastasis and micrometastasis were defined according to the TNM classification.

The pathological features of the patients are summarized in Table I. Histopathological examination detected the following types of breast cancer: ductal carcinoma in situ in 4/60 (6.6\%), invasive ductal carcinoma in 50/60 (83.3\%), invasive lobular carcinoma in 3/60 $(5 \%)$, mucinous carcinoma in $2 / 60(3.3 \%)$ and other in $1 / 60(1.7 \%)$. Based on the Bloom-Richardson grading scale, grade I was observed in 18/60 (36\%), II in $27 / 60(54 \%)$, and III in $5 / 60(10 \%)$.

\section{Sentinel lymph node processing}

A central slice of $1 \mathrm{~mm}$ was removed with a dedicated cutting device provided by SYSMEX and afterwards was fixed and embedded in paraffin for further histopathological examination based on HE staining (Fig. 1). The two other parts of the sentinel node were analysed in one reaction intraoperatively and the results were addressed to the surgeon within 30 to 40 minutes. In our study lymph nodes were simply homogenised in a special homogenising reagent, Lynorhag, $\mathrm{pH} 3.5$ (Sysmex, Kobe, Japan). The liquid phase was taken and inserted in the RD-100i, which automatically performs pipetting, amplification, and detection.

\section{The one step nucleic acid amplification method}

RT-LAMP reaction was carried out with the readyto-use Lynoamp kit (Sysmex, Kobe, Japan) on the RD-100i (Sysmex, Kobe, Japan) according to the manufacturer's instructions. According to the manufacturer's specifications (Sysmex), copy numbers between 250 and 5000 copies/ $\mu \mathrm{l}$ were designated as $(+)$, copy numbers higher than 5000 copies/ $\mu \mathrm{l}$ as $(++)$, and copy numbers lower than 250 copies/ $\mu$ l as (-). The total time required from the preparation of the lymph node until results are displayed is about 30 minutes for one lymph node and about 40 minutes for four lymph nodes.

\section{Results}

In the present study 74 SLN samples from 60 patients with breast cancer were investigated by both OSNA and HE based methods. The OSNA results were classified as negative $(<250$ copies $/ \mu \mathrm{l})$, micrometastases (from $\geq 250$ to $<5000$ copies/ $\mu \mathrm{l}$ ), or macrometastases $(\geq 5000$ copies $/ \mu \mathrm{l})$.

Table II shows OSNA results. Fourteen out of 74 samples contained a macrometastasis, expressing more than 5000 CK 19 mRNA copies/ $\mu \mathrm{l}(++), 10$ out of 74 contained a micrometastasis, expressing between 250 and $5000 \mathrm{CK} 19$ mRNA copies $/ \mu \mathrm{l}(+)$. Fifty samples were classified as negative $(<250$ copies $/ \mu \mathrm{l})$.

The OSNA method identified 24 SLN positive and 50 negative cases and histopathological methods 22 positive and 52 negative samples. We found 2 discordant

Table I. Pathological features of patients with breast cancer

\begin{tabular}{lcc}
\hline \multirow{2}{*}{ BreAst CANCER } & \multicolumn{2}{c}{ PATIENTS $(\mathrm{N}=60)$} \\
\cline { 2 - 3 } & $\mathrm{N}$ & $\%$ \\
\hline Stage & 18 & 36.0 \\
\hline I & 27 & 54.0 \\
\hline II & 5 & 10.0 \\
\hline III & & \\
\hline Histopathological type & 50 & 83.3 \\
\hline invasive ductal carcinoma & 3 & 5.0 \\
\hline invasive lobular carcinoma & 4 & 6.6 \\
\hline ductal carcinoma in situ & 2 & 3.3 \\
\hline mucinous carcinoma & 1 & 1.7 \\
\hline metaplastic carcinoma &
\end{tabular}




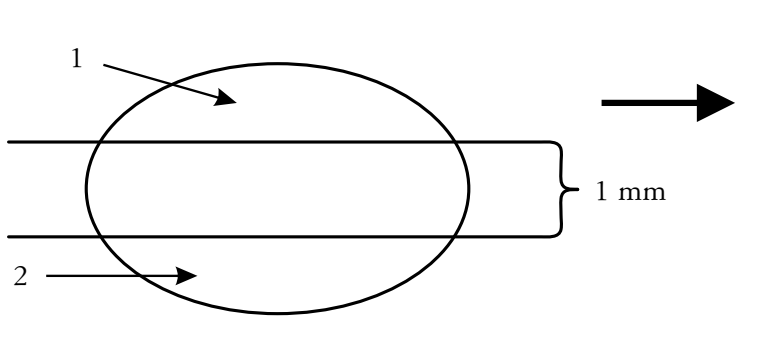

Whole lymph node

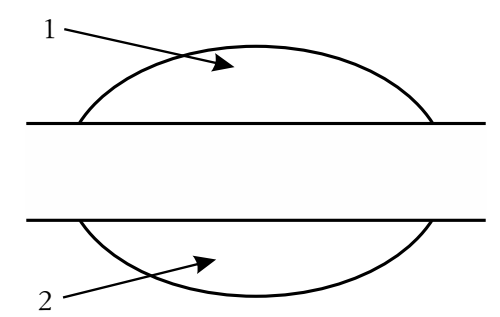

OSNA assay

Intraoperative

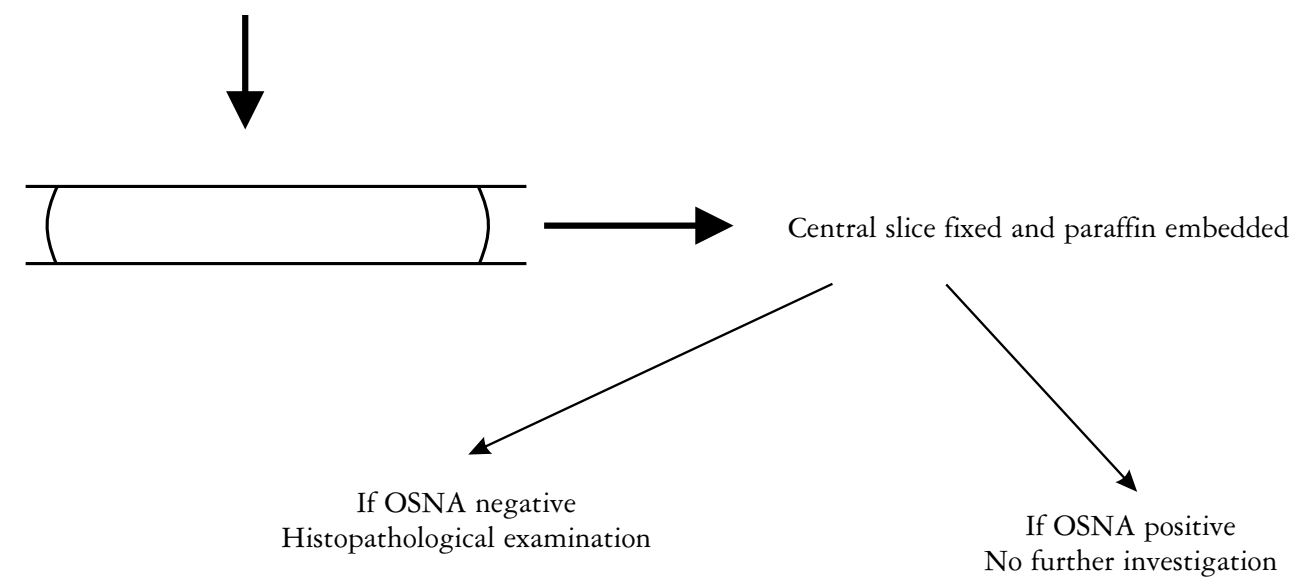

Postoperative

Fig. 1. Clinical study protocol

cases, 2 OSNA positive for micrometastases but HE negative (Table III). These discordances could be due to sampling bias such that a micrometastasis was confined to the slices used for OSNA or the slices used for HE staining.

\section{Discussion}

In the present study, we determined macrometastasis, micrometastasis and non-metastasis by measuring CK19 mRNA in histopathologically positive and negative lymph nodes using one-step nucleic acid amplification (OSNA). Our analysis by OSNA method is the first report in Poland.

The SLN metastasis is generally detected by conventional techniques such as intraoperative HE-based histopathological examination of frozen sections or cytological observation of touch imprints [11].

However, the sensitivity of these methods is not high. A recent study on the Japan and European populations documented that OSNA-CK19 may be a rapid intraoperative method for the detection of lymph node metastases in patients with gastric $\{12]$, colorectal $\{6$, $7]$ and breast cancer $[10,13,14]$.

These results indicate that the performance of the OSNA assay is better than that of one- and two-lev- el CK19 immunohistochemistry-based histopathologies and almost equivalent to three-level CK19 immunohistochemistry-based histopathology $[6,7,10$, 12-14].

In our work, a novel OSNA-CK19 method was compared to HE staining examination on 74 SLN of 60 breast cancer patients. Of the 22 histologically positive samples, 14 were attributed to macrometastases $(++)$ in the OSNA-CK19 assay and 8 to $\mathrm{mi}-$ crometastases $(+)$. Two samples negative in histopathology were positive in the OSNA method. In conclusion, the high sensitivity and specificity and the short analysis time (45 minutes) make OSNA-CK19 the method of choice for rapid assessment of lymph node metastases in breast cancer patients.

Our results are in line with the data from other reports, introducing a utility role of OSNA. Finally, it is postulated that OSNA may be used as an attractive intraoperative tool for the detection of lymph node metastases in breast cancer patients. Further studies, conducted on a larger group, are suggested to clarify this point.

The authors declare no conflict of interest. 
Table II. Results of the OSNA assay in 74 sentinel lymph nodes from 60 breast cancer patients

\begin{tabular}{|c|c|c|c|c|c|}
\hline $\begin{array}{l}\text { CASE } \\
(N=74)\end{array}$ & $\begin{array}{c}\text { CK19 } \\
\text { Conc. }\left(\text { COPIES } / \mu_{\mathrm{L}}\right)\end{array}$ & $\begin{array}{c}\text { CK19 } \\
\text { QUALITATIVE }\end{array}$ & $\begin{array}{l}\text { CASE } \\
(\mathrm{N}=74)\end{array}$ & $\begin{array}{c}\text { CK19 } \\
\text { Conc. }\left(\text { COPIES } / \mu_{\mathrm{L}}\right)\end{array}$ & $\begin{array}{c}\text { CK19 } \\
\text { QuALITATIVE }\end{array}$ \\
\hline 1. & $<2.5 \mathrm{E}+02$ & $(-)$ & 38. & $<2.5 \mathrm{E}+02$ & $(-)$ \\
\hline 2. & $<2.5 \mathrm{E}+02$ & $(-)$ & 39. & $<2.5 \mathrm{E}+02$ & $(-)$ \\
\hline 3. & $<2.5 \mathrm{E}+02$ & $(-)$ & 40. & $2.3 \mathrm{E}+03$ & $(+)$ \\
\hline 4. & $<2.5 \mathrm{E}+02$ & $(-)$ & 41. & $<2.5 \mathrm{E}+02$ & $(-)$ \\
\hline 5. & $<2.5 \mathrm{E}+02$ & $(-)$ & 42. & $<2.5 \mathrm{E}+02$ & $(+)$ \\
\hline 6. & $<2.5 \mathrm{E}+02$ & $(-)$ & 43. & $<2.5 \mathrm{E}+02$ & $(-)$ \\
\hline 7. & $4.1 \mathrm{E}+06$ & $(++)$ & 44. & $<2.5 \mathrm{E}+02$ & $(-)$ \\
\hline 8. & $2.8 \mathrm{E}+06$ & $(++)$ & 45. & $<2.5 \mathrm{E}+02$ & $(-)$ \\
\hline 9. & $<2.5 \mathrm{E}+02$ & $(-)$ & 46. & $<2.5 \mathrm{E}+02$ & $(-)$ \\
\hline 10. & $3.4 \mathrm{E}+06$ & $(++)$ & 47. & $<2.5 \mathrm{E}+02$ & $(-)$ \\
\hline 11. & $1.4 \mathrm{E}+06$ & $(++)$ & 48. & $5.4 \mathrm{E}+02$ & $(+)$ \\
\hline 12. & $5.4 \mathrm{E}+04$ & $(++)$ & 49. & $<2.5 \mathrm{E}+02$ & $(-)$ \\
\hline 13. & $<2.5 \mathrm{E}+02$ & $(-)$ & 50. & $<2.5 \mathrm{E}+02$ & $(-)$ \\
\hline 14. & $<2.5 \mathrm{E}+02$ & $(-)$ & 51. & $<2.5 \mathrm{E}+02$ & $(-)$ \\
\hline 15. & $<2.5 \mathrm{E}+02$ & $(-)$ & 52. & $<2.5 \mathrm{E}+02$ & $(-)$ \\
\hline 16. & $<2.5 \mathrm{E}+02$ & $(-)$ & 53. & $<2.5 \mathrm{E}+02$ & $(-)$ \\
\hline 17. & $<2.5 \mathrm{E}+02$ & $(-)$ & 54. & $<2.5 \mathrm{E}+02$ & $(-)$ \\
\hline 18. & $<2.5 \mathrm{E}+02$ & $(-)$ & 55. & $<2.5 \mathrm{E}+02$ & $(-)$ \\
\hline 19. & $<2.5 \mathrm{E}+02$ & $(-)$ & 56. & $<2.5 \mathrm{E}+02$ & $(-)$ \\
\hline 20. & $1.3 \mathrm{E}+04$ & $(++)$ & 57. & $<2.5 \mathrm{E}+02$ & $(-)$ \\
\hline 21. & $<2.5 \mathrm{E}+02$ & $(+)$ & 58. & $<2.5 \mathrm{E}+02$ & $(-)$ \\
\hline 22. & $<2.5 \mathrm{E}+02$ & $(-)$ & 59. & $<2.5 \mathrm{E}+02$ & $(-)$ \\
\hline 23. & $<2.5 \mathrm{E}+02$ & $(-)$ & 60. & $2.3 \mathrm{E}+04$ & $(++)$ \\
\hline 24. & $1.2 \mathrm{E}+06$ & $(++)$ & 61. & $<2.5 \mathrm{E}+02$ & $(-)$ \\
\hline 25. & $<2.5 \mathrm{E}+02$ & $(-)$ & 62. & $2.9 \mathrm{E}+05$ & $(++)$ \\
\hline 26. & $6.6 \mathrm{E}+04$ & $(++)$ & 63. & $1.0 \mathrm{E}+06$ & $(++)$ \\
\hline 27. & $<2.5 \mathrm{E}+02$ & $(-)$ & 64. & $<2.5 \mathrm{E}+02$ & $(-)$ \\
\hline 28. & $<2.5 \mathrm{E}+02$ & $(-)$ & 65. & $<2.5 \mathrm{E}+02$ & $(-)$ \\
\hline 29. & $<2.5 \mathrm{E}+02$ & $(-)$ & 66. & $<2.5 \mathrm{E}+02$ & $(-)$ \\
\hline 30. & $1.0 \mathrm{E}+04$ & $(++)$ & 67. & $<2.5 \mathrm{E}+02$ & $(-)$ \\
\hline 31. & $4.4 \mathrm{E}+03$ & $(+)$ & 68. & $5.5 \mathrm{E}+02$ & $(+)$ \\
\hline 32. & $<2.5 \mathrm{E}+02$ & $(+)$ & 69. & $6.5 E+03$ & $(++)$ \\
\hline 33. & $3.4 \mathrm{E}+03$ & $(+)$ & 70. & $<2.5 \mathrm{E}+02$ & $(-)$ \\
\hline 34. & $3.4 \mathrm{E}+03$ & $(+)$ & 71. & $<2.5 \mathrm{E}+02$ & $(-)$ \\
\hline 35. & $<2.5 \mathrm{E}+02$ & $(-)$ & 72. & $<2.5 \mathrm{E}+02$ & $(-)$ \\
\hline 36. & $1.4 \mathrm{E}+06$ & $(++)$ & 73. & $<2.5 \mathrm{E}+02$ & $(-)$ \\
\hline 37. & $<2.5 \mathrm{E}+02$ & $(-)$ & 74. & $1.1 \mathrm{E}+03$ & $(+)$ \\
\hline
\end{tabular}

Negative $-(<250$ copies $/ \mu l)$, micrometastases $+($ from $\geq 250$ to $<5000$ copies $/ \mu l)$, macrometastases $++(\geq 5000$ copies $/ \mu l)$.

Table III. Comparison between OSNA assay results and histological examination

\begin{tabular}{|c|c|c|c|c|}
\hline & \multicolumn{4}{|c|}{ RESUlT OF SLN ( $=74)$ ASSESSMENT } \\
\hline & \multicolumn{2}{|c|}{ POSITIVE } & \multicolumn{2}{|c|}{ NEGATIVE } \\
\hline & $\mathbf{N}$ & $\%$ & $\mathbf{N}$ & $\%$ \\
\hline histological examination & $22 / 74$ & 29.70 & $52 / 74$ & 70.30 \\
\hline OSNA & $24 / 74$ & 32.40 & $50 / 74$ & 67.60 \\
\hline
\end{tabular}




\section{References}

1. Yager JD, Davidson NE. Estrogen carcinogenesis in breast cancer. New Engl J Med 2006; 354: 270-282.

2. Luini A, Gatti G, Ballardini B, et al. Development of axillary surgery in breast cancer. Ann Oncol 2005; 16: 259-262.

3. Nissan A, Jager D, Roystacher M, et al. Multimarker RT-PCR assay for the detection of minimal residual disease in sentinel lymph nodes of breast cancer patients. Br J Cancer 2004; 94: 681-685.

4. Chu PG, Weiss LM. Keratin expression in human tissues and neoplasms. Histopathology 2002; 40: 403-439.

5. Fuchs E, Weber K. Intermediate filaments: structure, dynamics, function, and disease. Annu Rev Biochem 1994: 63: 345-382.

6. Yamamoto H, Sekimoto M, Oya M, et al. OSNA-based novel molecular testing for lymph node metastases in colorectal cancer patients: results from a multicenter clinical performance study in Japan. Ann Surg Oncol 2011; 18: 1891-1898.

7. Croner RS, Schellerer V, Demund H, et al. One step nucleic acid amplification (OSNA) - a new method for lymph node staging in colorectal carcinomas. J Transl Med 2010; 6: 8-83.

8. Godey F, Leveque J, Tas P, et al. Sentinel lymph node analysis in breast cancer: contribution of one-step nucleic acid amplification (OSNA). Breast Cancer Res Treat 2012; 131: 509-516.

9. Castellano I, Macrì L, Deambrogio C, et al. Reliability of whole sentinel lymph node analysis by one-step nucleic Acid amplification for intraoperative diagnosis of breast cancer metastases. Ann Surg 2012; 255: 334-342.

10. Osako T, Iwase T, Kimura K, et al. Accurate staging of axillary lymph nodes from breast cancer patients using a novel molecular method. Br J Cancer 2011; 105: 1197-1202.

11. Torrenga H, Rahusen FD, Meijer S, et al. Sentinel node investigation in breast cancer: detailed analysis of the yield from step sectioning and immunohistochemistry. J Clin Pathol 2001; 54 : 550-552.

12. Yaguchi Y, Sugasawa H, Tsujimoto H, et al. One-step nucleic acid amplification (OSNA) for the application of sentinel node concept in gastric cancer. Ann Surg Oncol 2011; 18: 2289-2296.

13. Taniyama K, Motoshita J, Sakane J, et al. Combination analysis of a whole lymph node by one-step nucleic acid amplification and histology for intraoperative detection of micrometastasis. Pathobiology 2006; 73: 183-191.

14. Bernet L, Cano R, Martinez M, et al. Diagnosis of the sentinel lymph node in breast cancer: a reproducible molecular method: a multicentric Spanish study. Histopathology 2011; 58: 863-869.

\section{Address for correspondence}

\section{Beata Smolarz}

Laboratory of Molecular Genetics

Department of Pathology

Institute of Polish Mother's Memorial Hospital

Rzgowska 281/289

93-338 Lodz, Poland

tel. +48422711280

e-mail: smolbea@wp.pl 